\title{
Knowledge Management Practices and Performance of Academic Libraries: A Case of Mount Kenya University, Kigali Campus Library
}

\author{
Wamalwa Lucas Wanangeye, Benard Omallah George* \\ Department of Library, Mount Kenya University-Kisii Campus, Kenya
}

Copyright $(2016$ by authors, all rights reserved. Authors agree that this article remains permanently open access under the terms of the Creative Commons Attribution License 4.0 International License

\begin{abstract}
This research sought to determine, assess and evaluate the knowledge management practices and performance in academic libraries. The researcher chose the case study of Mount Kenya University, Kigali Campus library. The general objective of this study was to understand the knowledge management practices used in enhancing the performance of academic libraries. Specifically, the researcher identified major drivers of Knowledge Management (KM) practices in academic libraries; analyzed the KM activities needed to enhance the academic library for proper KM practice; and determined the challenges that might face the academic librarians in implementing KM. The study population included all the library staff in the university. The researcher used census to sample the total population of all the university library staff. Data was collected using questionnaires and data analysis procedures involved editing to verify the coherent of respondents in answering the questionnaires, coding to summarize and simplify the work of processing data and finally graphical representation to make statistical frequency distributions.
\end{abstract}

Keywords Knowledge, Knowledge Management (KM), Academic Libraries, Information

\section{Introduction}

Knowledge has been increasingly seen as a key competitive resource in organizations and this has influenced selection and recruitment practices in many organizations. Indeed, as Davenport and Prusak (1998) reported: 'companies hire for experience more often than for intelligence or education because they understand the value of knowledge that has been developed and proven over time'. Knowledge can either be explicit or tacit knowledge; it is the implicit or tacit knowledge which is conceptual knowledge which comes from experience and gives rise to 'wisdom' that organization seek to add value to their processes. The conversion of implicit into explicit knowledge forms a powerful contribution to sustainable competitive advantage for organizations. But this knowledge alone will not foster a learning organization; rather it is through the sharing of knowledge that organizational learning is facilitated.

Academic libraries have transformed drastically from Machine Readable Catalogue (MARC) and circulation desk to metadata and web information, print collection and inter library loans to online databases and e-resources, quiet areas to learning and knowledge commons, bibliographic instruction to information literacy and life-long learning, information management to knowledge management and so on. Accordingly, the roles of academic librarians have changed radically at both library practitioners and library school educators' levels. They are no more traditional information protectors and managers. Open access, knowledge management, digital scholarship, institutional repositories are all often owned by the libraries and the librarians.

Knowledge Management (KM) has increased in popularity and credibility as a management tool, as well as a research discipline, over the past decade. There have been concerns about whether KM is simply a fad, and researchers and academics have debated its faddish like characteristics. The researchers, and this paper adopts the view that KM certainly is not a fad for different reasons, and agree with Stankosky's view that one of these reasons is that the knowledge-economy is here to stay (Stankosky, 2005). Knowledge Management is therefore said to be slowly but surely capturing the attention of many organizations in a quest for competitive advantage and service delivery (Boahene, 2003). The question as to whether universities are ready for Knowledge Management practices becomes the perspective from which the researcher seeks to investigates the use of Knowledge Management practices in enhancing service delivery within Higher Education, and presents the nature of academics and universities, and the related challenges for KM implementation within this context. 
Review the library literature on KM in libraries reveals that, all types of libraries are applying some KM principles in the provision of library services. Townley (2001) pointed out that special libraries, especially business and corporate libraries, are taking the lead on KM research; and academic libraries, public libraries and digital libraries are in the limelight. The literature review also reveals that within academic libraries, public services are taking the lead in the research and implementation of KM (Wen 2005).

Mount Kenya University is one of the most recognized and fast growing private Universities in East Africa. Just like other Universities, it offers different courses ranging from Technology, Business, Health, Communication, Engineering and other faculties both national and international. Having received a Customer Service Charter (CSC), the University is therefore keeping focus on the mission, vision and philosophy in an effort to satisfy customers without losing sight of the expectations of other stake holders according to the MKU Charter, (2011). It is in this perspective that the researcher chose the Mount Kenya University, Kigali Campus as the case study.

\section{Literature Review}

According to a study carried out by Sarrafzadeh, Martin, \& Hazeri (2010), 82.2\% Library Information Science (LIS) professionals regarded $\mathrm{KM}$ as a survival factor for libraries to respond to challenges they face in a continuously changing environment. Since KM equips academic libraries with ample amenities to satisfy the incessantly changing library customer needs, it is a survival kit and a strategic tool for academic libraries. Increased visibility of libraries: Libraries often have a poor image; they are not visible to their parent organization and work in isolation. The ultimate aim of $\mathrm{KM}$ is to achieve an organization's mission. Therefore, all parts of an organization (including libraries) must ensure that KM contributes towards the realization of the organizational mission and vision. Adoption of KM could assist library and information professionals in meeting user needs aligned with the organization's strategic goals and objectives. In addition, KM provides libraries with the opportunity to collaborate with other units in their organizations and hence become more integrated into corporate operations and enhance their overall visibility within the organization (Sarrafzadeh, Martin, \& Hazeri, 2010). Thus, KM endows academic librarians with various platforms to collaborate with academia, such as playing a leading role in electronic and open access publications by providing guidance on copyright issues, and self-archiving published articles in institutional repositories.

Academic libraries are perceived as knowledge creating organizations, as a system of integrated activities and business processes that work together collaboratively to facilitate accomplishing overall organizational goals (Daneshgar \& Parirokh, 2007). Academic libraries are the treasure house of knowledge to cater for the needs of scholars, scientists, technocrats, researchers, students and others who are in the mainstream of higher education (Guru et al, 2009).

Librarians are acknowledged as knowledge creators through content management, organization of knowledge, and evaluating the validity and reliability of information obtained from unfamiliar sources (Sinotte, 2004). Librarians bring a set of values that are fundamental to the long-term survival of scholarship. Librarians care about access and understand that some resources may have value to disciplines and time periods beyond their initiation (Case, 2011). Academia stimulates the creation and transmission of knowledge, and academic libraries have played a significant role in supporting such activities (Kim \& Abbas, 2010). Thus, academic libraries are knowledge creating and knowledge-based organizations. Debowski (2006) puts emphasis on the need for cultivation of new knowledge competencies through the development of appropriate work-based learning programmes for librarians as early advocates of the knowledge management. Increased value of knowledge in the knowledge economy: In a study undertaken by Roknuzzaman \& Umemoto (2009), knowledge economy was considered to be one of the important drivers for libraries' movement towards KM. The above authors have noted that the value of knowledge has always been central to library practice, but the new knowledge-based economy places its significance more than ever before.

According to the experts, human knowledge is doubling every thirty two hours. Due to this, we are in a state of information overload and decay of existing knowledge, which is continuously replaced with new knowledge. According to Israel (2010), this information explosion affects library users in a variety of ways; it damages health, leads towards bad decision making and creates information anxiety. In the same way, the information explosion confronts university librarians with many challenges; such as, selection and acquisition of library resources, organization of acquired resources, collection development, cataloguing, and reference services. At the same time it enables users to select from a wide range of resources (Israel, 2010), which creates competition. Information explosion and knowledge growth calls for innovative approaches to manage the right knowledge. Since KM emphasizes on updating of knowledge regularly in order to remove obsolete information and avail the most updated information, using the KM systems academic librarians can overcome the problem of information explosion to a greater extent.

\section{Research Methodology}

The researcher used both descriptive and analytical research design based on both qualitative and quantitative data. Issues related to Knowledge Management practices and performance in academic libraries, especially MKU were described and analyzed. The target population of the 
research was the general library staff of the Mount Kenya University Library, especially fulltime staffs. The researcher decided to use the census technique as a sampling technique because the number of the targeted population, the librarians, was small. The researcher used questionnaires, interviews and observation to collect data.

\section{Results and Discussions}

All respondents were employees of MKU Library Kigali campus and each had an email address. They all had computers and internet access at the time of this study. On examining the respondents, six were male and represented $(60 \%)$ and four were female who represented $(40 \%)$. From the ten distributed questionnaires, received were only seven (70\%) who responded, three of them (30\%) didn't respond.
Table 1 represents the gender distribution of the respondents.

Table 1. Gender distribution of the respondents

\begin{tabular}{|c|c|}
\hline Gender & Frequency \\
\hline Male & 6 \\
\hline Female & 4 \\
\hline Total & 10 \\
\hline
\end{tabular}

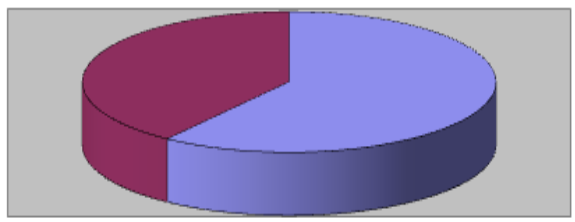

amale afemale

The distribution of the Gender is as shown above, 6 that amounts $60 \%$ of the male and 4 amounting $40 \%$ of the female, which amounted to the total of 10 hence (100\%).

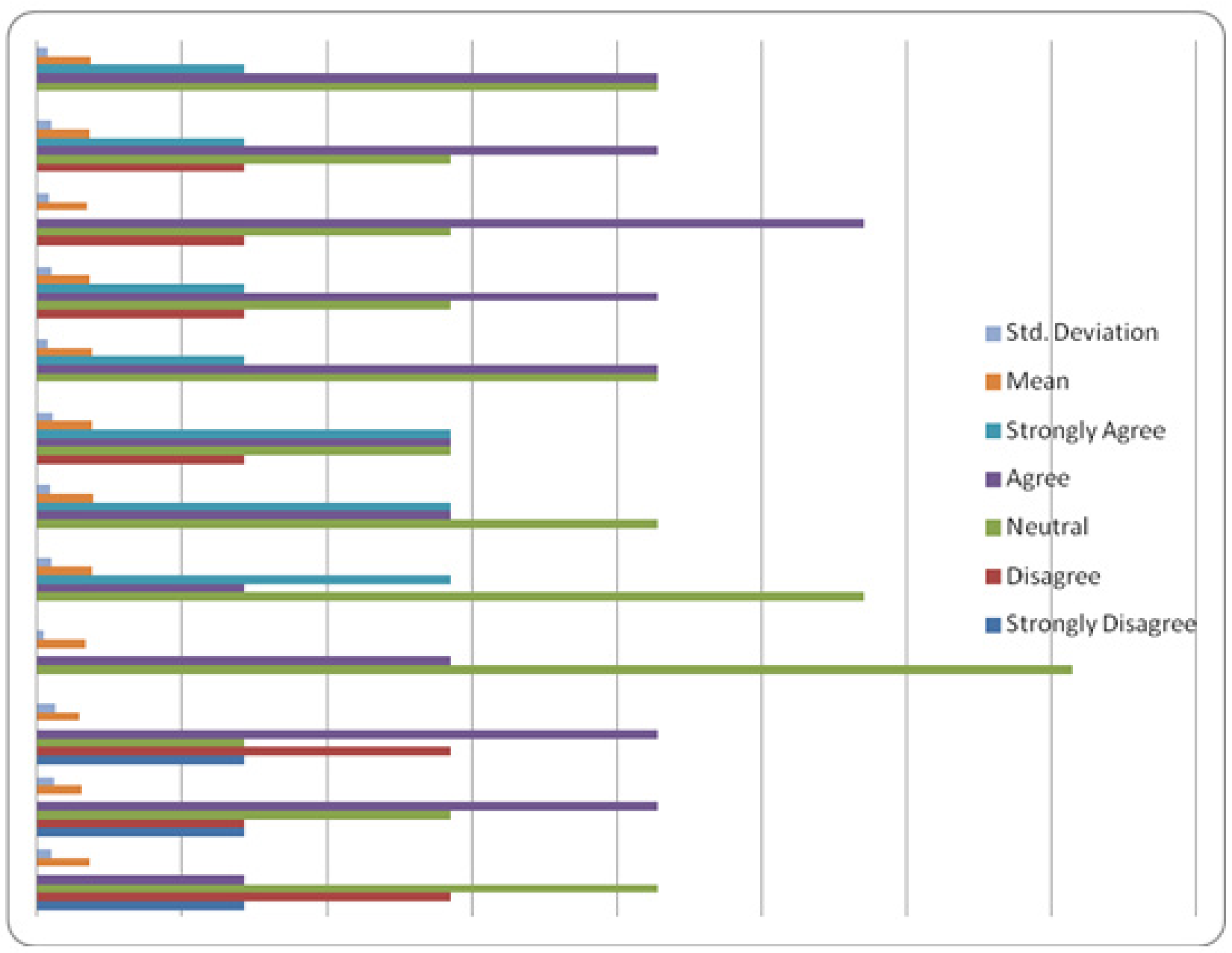

Figure 1. Major drivers of KM practices in academic libraries. 
Table 2. Respondents rating averages on major drivers of KM in academic libraries

\begin{tabular}{|c|c|c|c|c|c|c|c|}
\hline Statement & $\begin{array}{c}\text { Strongly } \\
\text { Disagree }\end{array}$ & Disagree & Neutral & Agree & $\begin{array}{c}\text { Strongly } \\
\text { Agree }\end{array}$ & $\begin{array}{c}\text { Mean } \\
\text { Deviation }\end{array}$ \\
\hline To improve library services & 14.28571 & 28.57143 & 42.85714 & 14.28571 & 0.0 & 3.571429 & 0.9759 \\
\hline To improve library productivity & 14.28571 & 14.28571 & 28.57143 & 42.85714 & 0.0 & 3 & 1.154701 \\
\hline $\begin{array}{c}\text { To produce more with less due to } \\
\text { dwindling library budget }\end{array}$ & 14.28571 & 28.57143 & 14.28571 & 42.85714 & 0.0 & 2.857143 & 1.214986 \\
\hline To leverage existing knowledge & 0.0 & 0.0 & 71.42857 & 28.57143 & 0.0 & 3.285714 & 0.48795 \\
\hline Achieve the library goals efficiently. & 0.0 & 0.0 & 57.14286 & 14.28571 & 28.57143 & 3.714286 & 0.95119 \\
\hline To manage information explosion & 0.0 & 0.0 & 42.85714 & 28.57143 & 28.57143 & 3.857143 & 0.899735 \\
\hline To make informed decisions & 0.0 & 14.28571 & 28.57143 & 28.57143 & 28.57143 & 3.714286 & 1.112697 \\
\hline To establish best practices & 0.0 & 0.0 & 42.85714 & 42.85714 & 14.28571 & 3.714286 & 0.755929 \\
\hline To avoid duplication of efforts & 0.0 & 14.28571 & 28.57143 & 42.85714 & 14.28571 & 3.571429 & 0.9759 \\
\hline $\begin{array}{c}\text { Improve my job performance. } \\
\text { Enables me to react more quickly to } \\
\text { change. }\end{array}$ & 0.0 & 14.28571 & 28.57143 & 57.14286 & 0.0 & 3.428571 & 0.786796 \\
\hline $\begin{array}{c}\text { Speeds up the process decision } \\
\text { making }\end{array}$ & 0.0 & 14.28571 & 28.57143 & 42.85714 & 14.28571 & 3.571429 & 0.9759 \\
\hline
\end{tabular}

According to the Cronbach's Alpha statistics with a score of 0.8 is clear evidence that the questionnaire was smart. The table below defines major drivers of Knowledge management in academic libraries. A rating average means of 3.28 in the perception that leveraging existing indicates that most respondents were suggestive of being neutral than disagreeing or agreeing. A rating average of 3.42 explains that most respondents agree that job performance is a major driver of KM in academic libraries. Improving of library services was not agreed by respondents as a major driver of KM in academic libraries by the respondents. These rating averages are depicted in the figure below.

A rating of 58 confirms that major drivers of KM in academic libraries, as many agree that job performance are a major driver of KM. About 28 respondents totally disagree that making informed decisions is not a major driver of KM in academic libraries while 70 confirms to be neutral on whether the leverage of existing knowledge is a major driver of KM in academic libraries.

Table 3. KM Practices needed to enhance the academic library for proper KM practice.

\begin{tabular}{|c|c|c|c|c|c|c|c|}
\hline Statement & $\begin{array}{c}\text { Strongly } \\
\text { Disagree }\end{array}$ & Disagree & Neutral & Agree & $\begin{array}{c}\text { Strongly } \\
\text { Agree }\end{array}$ & Mean & $\begin{array}{c}\text { Std. } \\
\text { Deviation }\end{array}$ \\
\hline $\begin{array}{c}\text { Facilitates strong culture of } \\
\text { knowledge sharing. }\end{array}$ & 0.0 & 14.28571 & 0.0 & 71.42857 & 14.28571 & 3.857143 & 0.899735 \\
\hline $\begin{array}{c}\text { Focus on identifying personal } \\
\text { expertise. }\end{array}$ & 0.0 & 14.28571 & 42.85714 & 28.57143 & 14.28571 & 3.428571 & 0.9759 \\
\hline $\begin{array}{c}\text { Create system to capture the tacit } \\
\text { knowledge of employees. }\end{array}$ & 0.0 & 28.57143 & 57.14286 & 0.0 & 14.28571 & 3 & 1 \\
\hline $\begin{array}{c}\text { Availability of knowledge enabling } \\
\text { technology. }\end{array}$ & 14.28571429 & 14.28571 & 28.57143 & 42.85714 & 0.0 & 3 & 1.154701 \\
\hline $\begin{array}{c}\text { Survey of knowledge within the } \\
\text { library }\end{array}$ & 14.28571429 & 14.28571 & 28.57143 & 28.57143 & 14.28571 & 3.142857 & 1.345185 \\
\hline Focus on creativity and innovation & 14.28571429 & 14.28571 & 42.85714 & 14.28571 & 14.28571 & 3 & 1.290994 \\
\hline $\begin{array}{c}\text { Written knowledge management } \\
\text { policy. }\end{array}$ & 0.0 & 28.57143 & 28.57143 & 28.57143 & 14.28571 & 3.285714 & 1.112697 \\
\hline Strong partnership with other libraries & 14.28571429 & 14.28571 & 28.57143 & 28.57143 & 14.28571 & 3.142857 & 1.345185 \\
\hline $\begin{array}{c}\text { Identify knowledge required in next } \\
\text { five years. }\end{array}$ & 0.0 & 14.28571 & 42.85714 & 42.85714 & 0.0 & 3.285714 & 0.755929 \\
\hline Establish Knowledge Repository & 14.28571429 & 28.57143 & 28.57143 & 14.28571 & 14.28571 & 2.86 & 1.345 \\
\hline
\end{tabular}

To find out the activities that are needed to enhance the academic library for proper KM practices, questions about technology, innovation, creativity and expertise were raised. Most respondents disagreed with a mean of 3.8 that KM activities don't facilitate strong culture of knowledge sharing. They however strongly agreed that creating a system to capture the tacit knowledge of employees is one of the KM activities needed to enhance academic libraries for KM practices. Most of the respondents didn't agree on the establishment of the knowledge repository, as most of them were not sure. These perceptions are reflected in the table below 
Table 4. Challenges that might face the academic librarians in implementing KM

\begin{tabular}{|c|c|c|c|c|c|c|c|}
\hline Statement & $\begin{array}{c}\text { Strongly } \\
\text { Disagree }\end{array}$ & Disagree & Neutral & Agree & $\begin{array}{c}\text { Strongly } \\
\text { Agree }\end{array}$ & $\begin{array}{c}\text { Mean } \\
\text { Deviation }\end{array}$ \\
\hline Constant budget decline & 0.0 & 14.28571 & 42.85714 & 42.85714 & 0.0 & 3.285714 & 0.755929 \\
\hline Lack of incentives & 0.0 & 14.28571 & 28.57143 & 42.85714 & 14.28571 & 3.571429 & 0.9759 \\
\hline Inadequate staff training & 0.0 & 0.0 & 28.57143 & 71.42857 & 0.0 & 3.714286 & 0.48795 \\
\hline Limited expertise in KM & 0.0 & 0.0 & 57.14286 & 28.57143 & 14.28571 & 3.571429 & 0.786796 \\
\hline $\begin{array}{c}\text { Lack of clearly defined guidelines } \\
\text { on KM implementation }\end{array}$ & 0.0 & 0.0 & 71.42857 & 28.57143 & 0.0 & 3.285714 & 0.48795 \\
\hline Insufficient Technology & 0.0 & 0.0 & 42.85714 & 42.85714 & 14.28571 & 3.714286 & 0.755929 \\
\hline A lack of knowledge sharing culture & 0.0 & 0.0 & 14.28571 & 85.71429 & 0.0 & 3.857143 & 0.377964 \\
\hline $\begin{array}{c}\text { A lack of cooperation among } \\
\text { juniors and seniors }\end{array}$ & 0.0 & 0.0 & 14.28571 & 71.42857 & 14.28571 & 4 & 0.57735 \\
\hline $\begin{array}{c}\text { There is no difference in job } \\
\text { evaluation between those who } \\
\text { practice knowledge sharing and } \\
\text { those who do not. }\end{array}$ & 0.0 & 0.0 & 57.14286 & 28.57143 & 14.28571 & 3.571429 & 0.786796 \\
\hline $\begin{array}{c}\text { Lack of guidelines to support the } \\
\text { sharing of knowledge. }\end{array}$ & 0.0 & 0.0 & 28.57143 & 57.14286 & 14.28571 & 3.86 & 0.69 \\
\hline
\end{tabular}

A rating average of 3.85 reflects that the majority of the respondents agree that there is lack of knowledge sharing culture among the librarians, posing a challenge to academic librarians in implementing KM. An average rating of 3.28 also reflects that some respondents were neutral on lack of clearly defined guidelines on implementing the KM. A few respondents also disagreed that lack of incentives cannot pose a challenge to academic librarians in implementing the KM. This is demonstrated in the figure below.

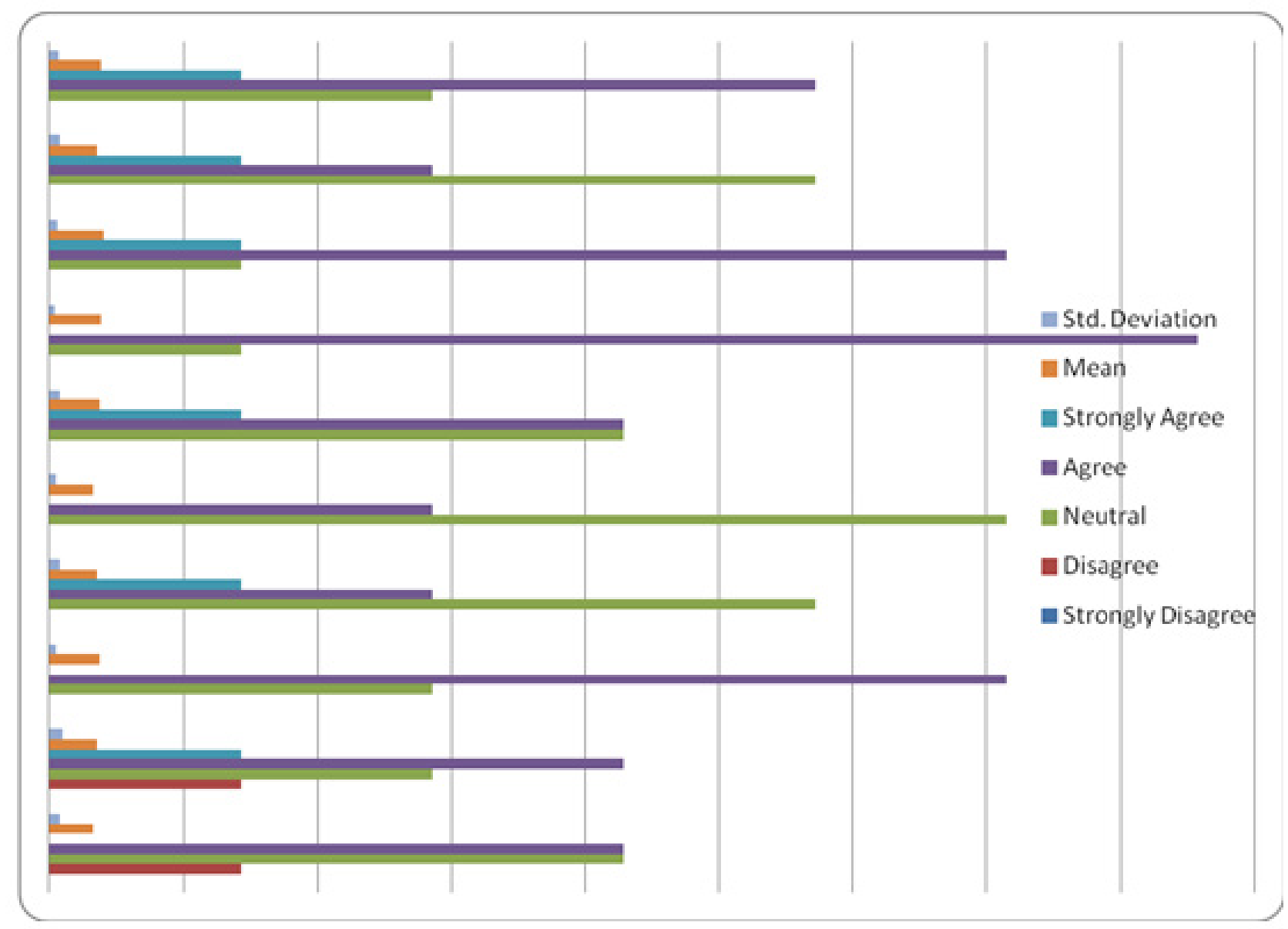

Figure 2. Challenges that might face the academic librarians in implementing KM 


\section{Conclusions and Recommendation}

The study investigated the KM practices and performance in academic libraries where the operational culture of the library was not KM. Its purpose to examine current library service in an environment where information was changing fast, and where there was competition from other sources such as the internet, had been achieved.

After discussing the implications of KM for the library, the suggestion made by Wen (2005) can be a practical way of getting the KM process in place:

The librarian should consider him/her self as the chief knowledge officer of the entire organization and should work together with the CIO, heads of the planning department, the computer and information technology center, the human resources management department, the finance department, etc. to design and develop such a system. Such a knowledge management system should be built on existing computer and information technology infrastructures, including upgraded intranet, extranet, and Internet, and available software programs to facilitate the capture, analysis, organization, storage, and sharing of internal and external information resources for effective knowledge exchange among users, resource persons (faculty, researchers, and subjects specialists, and so on.), publishers, government agencies, businesses and industries, and other organizations via multiple channels and layers.

\section{Recommendation}

It was recommended that the use of such a Web 2.0 application as delicious.com enables the accumulation and organization of all resources as tags in an individual's delicious.com account. Resources discovered with the use of web-quests, for example, can all be organized in one place. The use of web-quest style of instruction has the potential to enable students to make material gathered on the web their own, and integrate the data from their own practical experiences into their Constructive Action projects, but at the same time providing further validation for their conclusions from mostly web sources. This requires a certain amount of creativity and critical/reflective thinking to be successful. Faculty and librarians can provide coaching for this.

It was also recommended that even when the library did not have enough manpower to monitor or carry out all the duties that a fully functional library could, library user feedback can be used to improve products/services in the library. While some interview participants noted that the factors contributing to the inadequate state of library service included the negative attitudes and lack of awareness of the importance of library resources by some of the faculty, the library can use existing know-how and collaboration in a creative manner for new applications. The library can also continuously attempt to discover the service problems that cause gaps between targets and achievements. It is therefore practical for the library to try to counter dysfunctional beliefs within the university by utilizing multi-disciplinary teams to perform tasks and/or make decisions. Additionally, through classifying documents, the library has capabilities to integrate its knowledge across different subject areas, thus provide knowledge in a seamless manner.

\section{REFERENCES}

[1] Abbot, R. (2004). Subjectivity as a concern for information science: a Popperian perspective. Journal of Information Science, 30(2): 95-106.

[2] Abell, A. (2000). Skills for knowledge environments. The Information Management Journal, 34(3): 33-41.

[3] Abram, S. (2008). Evolution to revolution to chaos? Reference in transition. Internet Librarian International, 16(8). Available: http://www.infotoday.com/searcher/sep08/Abram.shtml (accessed 25/01/2009).

[4] Bailey, C.W. (2005). The role of reference librarians in institutional repositories. Reference Services Review, 33(3): 259-267. Available: http://www.digital-scholarship.org/cwb/ reflibir.pdf (accessed 04/06/2010).

[5] Baker, L.M. (2006). Observation: a complex research method. Library Trends, 55(1): 171-189. 317

[6] Barquin, R. (2001). What is knowledge management? Knowledge and innovation. Journal of the KMCI, 1(2): 127-143.

[7] Caracelli, V. J. \& Greene, J.C. (1993). Data analysis for mixed-method evaluation designs. Educational Evaluation and Policy Analysis, 15(2): 195-207.

[8] Carlin, A. P. (2003). Disciplinary debates and bases of interdisciplinary studies: the place of research ethics in library and information science. Library \& Information Science Research, 25(1): 3-18.

[9] Carpenter, C. \& Steiner, S. (2005). Using Web 2.0 technologies to push e-resources. Available: http://smartech.gatech.edu/bitstream/1853/13640/2/236-fri-1 1_05.pdf (accessed 01/02/2008).

[10] Daud, S., Rahim, R.E.A. \& Alimun, R. (2008). Knowledge creation and innovation in classroom. International Journal of Social Sciences, 3(1): 75-79.

[11] Davenport, T. H. \& Prusak, L. (1998). Working knowledge: how organizations manage what they know. Boston, Mass.: Harvard Business School Press.

[12] Mount Kenya University Schedule and Statutes (2012).

[13] Stankosky, M. (2005) Advances in Knowledge Management: University Research toward an Academic discipline, in Stankosky, M. (Ed.) Creating the Discipline of Knowledge Management. Washington, Elsevier Butterworth-Heinemann. 